\title{
The Effects of One-Sided vs. Two-Sided Review Valence on Electronic Word of Mouth (e-WOM): The Moderating Role of Sponsorship Presence
}

Jihye Park

Youjae Yi

Dawon Kang

Follow this and additional works at: https://amj.kma.re.kr/journal

Part of the Marketing Commons

\section{Recommended Citation}

Park, Jihye; Yi, Youjae; and Kang, Dawon (2019) "The Effects of One-Sided vs. Two-Sided Review Valence on Electronic Word of Mouth (e-WOM): The Moderating Role of Sponsorship Presence," Asia Marketing Journal: Vol. 21 : Iss. 2 , Article 1.

Available at: https://doi.org/10.15830/amj.2019.21.2.1

This Article is brought to you for free and open access by Asia Marketing Journal. It has been accepted for inclusion in Asia Marketing Journal by an authorized editor of Asia Marketing Journal. 


\title{
The Effects of One-Sided vs. Two-Sided Review Valence on Electronic Word of Mouth (e-WOM): The Moderating Role of Sponsorship Presence*
}

\author{
Jihye Park ${ }^{* *}$ \\ Youjae $\mathrm{Yi}^{* * *}$ \\ Dawon Kang****
}

Prior studies on the effects of online consumer reviews have mainly focused on review valence, but little research has investigated how two-sided (both positive and negative) and one-sided (only positive) reviews influence consumers' response to online review. In addition, little attention has been paid to how sponsorship presence (firm-sponsored reviews vs. consumer-voluntary reviews) influences individuals' attitude toward online review. Unlike consumer-voluntary reviews without any monetary incentive, firm-sponsored reviews include messages about brands providing monetary compensation. This study examines whether review valence (two-sidedness vs. onesidedness) influences attitude toward online review via its influence on review credibility. Further, this study examines whether sponsorship presence affects when review valence influences attitude toward review. Thus, this research investigates the effect of review valence on attitude toward review and the moderating role of sponsorship presence in the relationship between review valence and attitude toward review. The first experiment reveals that attitude toward review is more favorable when the review is two-sided (vs. one-sided). The second study demonstrates that differences between the two-sided and the one-sided review occur only for firm-sponsored reviews, not for consumer-voluntary reviews. The theoretical and practical implications are also discussed.

Key words: e-WOM, online consumer reviews, review valence, sponsorship presence, review credibility, attitude

\footnotetext{
* This research was supported by the Institute of Management Research, Seoul National University.

** College of Business Administration, Seoul National University

*** College of Business Administration, Seoul National University (youjae@snu.ac.kr), Corresponding Author

**** College of Business Administration, Seoul National University
} 


\section{Introduction}

The emergence of the Internet has incredibly changed the way consumers communicate with other consumers (Granitz \& Ward, 1996). With the use of the Internet, consumers easily publish their opinions by providing their thoughts, feelings, and viewpoints on products and services to the public (Schindler \& Bickart, 2005), leading to the appearance of new forms of word-of-mouth: that is, electronic word-of-mouth (referred to as e-WOM). The e-WOM exists on a variety of online channels such as blogs, e-mails, review websites, virtual communities, and SNSs (Dwyer 2007; Hung \& Li 2007; Phelps et al. 2004; Thorson \& Rodgers 2006). As a form of e-WOM, online consumer reviews play several important roles such as delivering product information and recommending a product. Thus, online consumer reviews can have a strong impact on consumers' attitude and behaviors in the decision-making context (Park \& Lee, 2007).

Prior research on $\mathrm{e}^{-W O M}$ has studied the effects of online reviews in terms of review valence (Clemons, Gao, \& Hitt, 2006; Gershoff, Mukherjee, \& Mukhopadhyay, 2003; Herr et al., 1991; Lee, Rodgers, \& Kim, 2009; Skowronski \& Carlston, 1989; Xue \& Zhou, 2010; Yang \& Mai, 2010), review quantity (Chen, Wu, \& Yoon, 2004; Duan, Gu, \& Whinston, 2008), and review attribute (Klein \& Ford, 2003;
Ratchford, Lee, \& Talukdar, 2003; Yoon \& Kim, 2001). Review valence (positive vs. negative information) has been most frequently studied as a factor which determines consumers' responses to online reviews. Nevertheless, previous results on this topic have been mixed (Lee \& Koo, 2012). On the one hand, some researchers supported that negative information has a greater influence than positive information in judgments (Herr et al., 1991; Lee et al., 2009; Xue \& Zhou, 2010; Yang \& Mai, 2010), which is referred to as 'negativity effects (negativity bias).' On the other hand, other researchers asserted 'positivity effects (positivity bias), which is a reversal of negativity effects (Clemons, Gao, \& Hitt, 2006; Gershoff, Mukherjee, \& Mukhopadhyay, 2003; Lee et al., 2009; Skowronski \& Carlston, 1989). These conflicting findings imply a need for further research.

Moreover, sponsorship presence regarding reviews should be examined as another important factor for a better understanding of the effects of online reviews. Although some online reviews are voluntarily generated without any compensation, firms often provide monetary compensation for online consumer reviews. Sponsored reviews refer to consumer-generated posts which are sponsored by a company and include messages concerning sponsored brands (Mutum \& Wang, 2010). Regulatory agencies have required online reviewers to disclose sponsorship information - that is, whether the online posting is sponsored or voluntary - in the sponsored posts. Despite 
the prominent impact of sponsorship presence, research has scarcely explored how consumervoluntary reviews and firm-sponsored reviews differ in affecting consumers' attitude. Therefore, the current research aims to examine the effects of review valence (two-sidedness vs. one-sidedness) on attitude toward review and the moderating role of sponsorship presence in the relationship between review valence and attitude toward review.

\section{Theoretical Background}

\subsection{Online Consumer Reviews as a Form of $\mathrm{e}^{-W O M}$}

The growth of the Internet has provided consumers with many opportunities to share their thoughts on products or services with others in interactive communication. One vital nature of e-WOM is that, unlike traditional WOM based on face-to-face communication, e-WOM enables consumers to acquire information from others whom they have little or no previous relationship with. Marketers also encounter a variety of strategic concerns regarding e-WOM. For example, how do consumers evaluate $\mathrm{e}^{-}$ WOM? How does consumer-generated information on e-WOM platforms affect consumers' purchase decisions? Under what circumstances do consumers recognize e-WOM information to be helpful and credible? How can companies facilitate benefits from e-WOM as a new medium?

Among the various types of e-WOM communications, online consumer reviews have been a new channel that is popular and significant to practitioners (Chen \& Xie, 2008). As an informant, online consumer reviews offer product information or recommendations about a product or a seller (Lee et al., 2008). Since online consumer reviews have increasingly become important for consumer purchase decisions and product sales, there has been much research on the effects of online reviews, suggesting the positive relationship between online reviews and consumers' purchase behavior (Chatterjee, 2001; Chen \& Xie, 2008; Duan, Gu, \& Whinston, 2008; Floyd, Freling, Alhoqail, Cho, \& Freling, 2014; Ho-Dac, Carson, \& Moore, 2013; Zhu \& Zhang, 2010).

\subsection{The Effects of Review Valence}

Online reviews are classified as positive or negative reviews regarding directionality (Lee et al., 2009). Past research has employed several theoretical approaches to address the effects of review valence (positive vs. negative information). However, the findings from prior studies are ambiguous. For instance, some studies showed that negative information has a stronger impact than positive information does (Herr et al., 1991; Lee et al., 2009; Xue \& Zhou, 2010; Yang \& Mai, 2010), which is 
referred to as 'negativity effects (negativity bias).' On the other hand, 'positivity effects (positivity bias)' have also been found in other studies (Clemons, Gao, \& Hitt, 2006; Gershoff, Mukherjee, \& Mukhopadhyay, 2003; Lee et al., 2009; Skowronski \& Carlston, 1989). For example, Doh \& Hwang (2009) found that positive sets of reviews have more effects on attitudes toward products and purchase intention than negative sets of reviews do. These mixed results on review valence suggest a need to study the effects of review valence at another level, which goes beyond either negativity or positivity effects.

Although prior studies have focused on one side by classifying review valence as either positive or negative, online reviews often include both positive and negative messages. The present study conceptualizes online reviews containing both positive and negative messages as two-sided reviews, similarly to two-sided advertisements. Past research on two-sided ads showed that the presence of negative information along with positive information increases message credibility (Crowley \& Hoyer, 1994; Pechmann, 1992). Consumers are likely to judge credibility of messages rather than unconditionally accepting messages while watching an ad. When consumers are exposed to a two-sided ad that includes negative aspects of a product, they might believe that the ad is trustworthy because the ad conveys disadvantageous contents in communicating product information (Golden
\& Alpert, 1987). Applying these findings on two-sided ads to the online consumer review context, online reviews may be evaluated as more trustworthy when it includes negative information about products. Negative messages contained in two-sided reviews might enhance review credibility that consumers perceive. Therefore, consumers are more likely to trust two-sided reviews containing both positive and negative messages rather than one-sided reviews including only positive messages.

Consumers' assessment on review credibility has been considered crucial in the effects of online consumer reviews. The present research predicts that consumers' attitude toward twosided online review would differ from their attitude toward one-sided review. According to Wathen \& Burkell (2002), consumers are likely to evaluate the credibility of messages when they read online reviews. Consumers tend to refuse the persuasive intent of messages if they recognize and judge that the messages are not credible enough (Lee \& Koo, 2012). Readers who believe the online reviews are reliable tend to have more assurance in adopting the online reviews for purchasing products (Nabi \& Hendrinks, 2003). Message credibility is positively related with positive evaluation (Cheung et al., 2009; Nabi \& Hendriks, 2003; Zhang \& Watts, 2008). Accordingly, two-sided (both positive and negative) review, compared to one-sided (only positive), review, is expected to enhance consumers' attitude toward online 
review because consumers judge two-sided review (vs. one-sided review) as more credible.

Taken together, the current study anticipates that two-sided reviews would lead consumers to perceive higher review credibility, and to have more favorable attitude toward online review. In contrast, consumers who read onesided review delivering only favorable messages of products or services are likely to perceive lower review credibility, resulting in a decrease in attitude toward online review. Our hypotheses are as follows.

H1: Consumers (readers) will have more positive attitude toward reviews when the reviews are two-sided (both positive and negative), compared to when the reviews are one-sided (only positive).

H2: Review credibility will mediate the relationship between review valence and attitude toward review.

\subsection{Moderating Role of Sponsorship Presence}

As already discussed, Internet has allowed people to interact with each other and share product information easily, leading to the rapid development of online review platforms. As online consumer reviews can have an enormous impact on consumer behavior, marketers have strategically used online reviews as a marketing tool (Mutum \& Wang, 2010). Managers often provide some online review channels such as personal blogs with monetary or non-monetary benefits in an attempt to encourage consumers to include messages regarding sponsored products or services (Forrest \& Cao, 2010; Zhu \& Tan, 2007). Such sponsored reviews refer to consumergenerated posts which are sponsored by a company and include messages concerning sponsored brands (Mutum \& Wang, 2010). On the contrary, consumer-initiated reviews are voluntary reviews written by consumers,

〈Figure 1〉 Conceptual Research Model ( $\mathrm{H} 1$ \& H2)

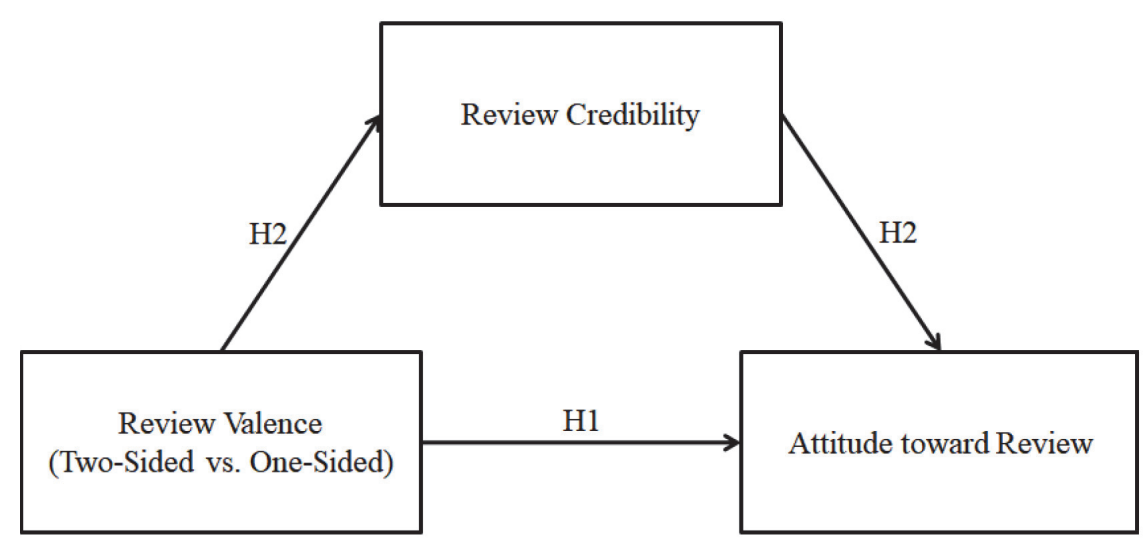

The Effects of One-Sided vs. Two-Sided Review Valence on Electronic Word of Mouth (e-WOM): The Moderating Role of Sponsorship Presence 5 
but not sponsored by a firm. Little prior research to date has examined sponsorship presence that is, whether online reviews are sponsored or voluntary - as a factor that can moderate the impact of review valence on attitude toward review. Thus, the current study explores whether the effects of review valence vary by sponsorship presence.

Sponsored reviews by consumers are a form of online consumer reviews (Forrest \& Cao, 2010). However, some researchers suggested that sponsored reviews are a form of online advertisement by marketers, not just a consumer review (Zhu and Tan, 2007). Although the reviewers who write sponsored reviews express their personal experience about products or services as a consumer, other consumers are likely to perceive the sponsored reviews as an advertisement in that the sponsorship information is disclosed in the posting. In recent years, regulatory agencies have made it mandatory for online reviewers to disclose sponsorship information (Petty \& Andrews, 2008; Rotfeld, 2008). Specifically, the Federal Trade Commission (FTC) in the U.S. has recommended that when posting on social networks such as Instagram, reviewers should display a hashtag that states sponsorship information. Similarly, the Fair Trade Commission (FTC) in South Korea has required online reviewers to reveal whether the reviews are sponsored or not. Due to these regulations, if the reviews are sponsored by a firm, reviewers should unveil the sponsorship statement in their posting. Consequently, sponsorship presence might negatively affect viewers' responses to online reviews. When exposed to firm-sponsored reviews, consumers are more likely to recognize sponsorship information as a cue for advertising. However, when exposed to consumer-voluntary reviews, consumers' perception may not be affected by the absence of sponsorship information. These differences may influence people's responses to online review. That is, those who read firm-sponsored review may perceive it as less reliable whereas those who read consumer-voluntary review may consider it more reliable.

Taken together, the current research proposes that the effects of review valence on attitude toward online review would differ by sponsorship presence. Specifically, the impact of review valence would be more prominent among those who read firm-sponsored reviews. This is because the sponsorship information may serve as a signal that makes consumers aware of it as advertising, and doubtful about its credibility. On the other hand, the impact of review valence would be less likely to occur for consumervoluntary reviews because consumer-voluntary reviews are generally expected to induce the judgment of higher credibility of messages.

H3: Sponsorship presence (i.e., firm-sponsored vs. consumer-voluntary reviews) will moderate the influence of review valence on review credibility and thus attitude 
toward review.

H3a: For firm-sponsored reviews, two-sided (compared to one-sided) reviews will yield higher review credibility, resulting in more positive attitude toward review.

H3b: For consumer-voluntary reviews, review valence (two-sided or one-sided), will not affect review credibility, resulting in no difference in attitude toward review.

The current research tests the hypotheses in two studies. Study 1 provides preliminary support for hypothesis 1 such that consumers (readers) have more positive attitude toward the review when reviews are two-sided, compared to when they are one-sided. Study 2 provides support for hypothesis 2 and 3 by replicating the above effect and providing evidence that review credibility underlies this effect. Also, study 2 examines sponsorship presence as a moderator of the above effect. These studies are described next.

\section{Study 1}

\subsection{Method}

\subsubsection{Pretest}

In order to develop two-sided and one-sided reviews as stimuli, a pretest was conducted with 32 respondents. The subjects were shown the online reviews (two-sided vs. one-sided) adapted from the real online consumer reviews

〈Figure 2〉 Conceptual Research Model (H3)

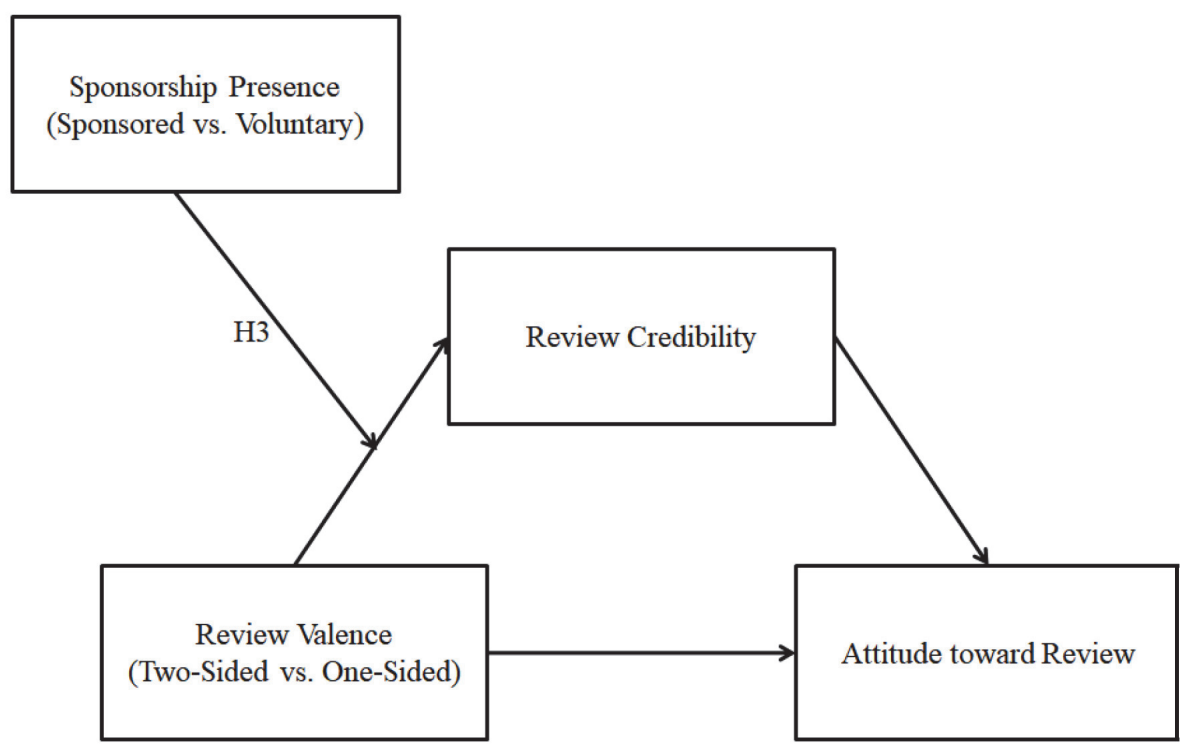


and were asked to rate the extent to which they felt that the assigned reviews describe the negative or positive aspects of the discussed object (the real brand "Plu Body Scrub") on a 7-point scale (Park \& Lee, 2007). The result suggested that there was no significant difference between the two-sided and one-sided conditions for the item 'I think the review reveals the positive aspects of the Plu Body Scrub' ( $M$ twosided $=4.79, M$ one-sided $=5.54, F(1,30)=$ 1.62, $p=.213$ ), whereas the two-sided condition rated higher than the one-sided condition for the item 'I think the review that I read reveals the negative aspects of the Plu Body Scrub' ( $M$ two-sided $=4.80, M$ one-sided $=3.00$, $F(1,30)=9.61, p<.05)$.

\subsubsection{Subjects, Design, and Procedure}

A scenario-based experiment was designed and 115 undergraduate and graduate students in South Korea were recruited in return for a small amount of incentives. They were assigned to one of two conditions (review valence: twosided vs. one-sided).

Respondents read a fictional scenario where they assumed that they are going to buy a body scrub and read one of several relevant reviews on the Internet. Then, they read a review depending on randomly assigned conditions. The stimuli were used as created in a pretest. Afterward, they were required to answer a series of questions about attitude toward review and demographics.

\subsubsection{Scales}

Attitude toward review was measured as an average of four 7-point items adapted from $\mathrm{Lu}$ et al. (2014). The items were "Do you really think you can get information about the Plu Body Scrub product in the above review?", "Do you think the above review is reliable?", "Do you think that the above review was written accurately?", and "Do you think the above review is telling the truth?" Reliability analysis revealed sufficient reliabilities with Cronbach's alpha of .86 .

Review valence was also measured for manipulation checks. Participants were asked to assess the extent to which they felt that the reviews describe the negative or positive aspects of the product on a 7 -point scale (Park \& Lee, 2007).

\subsection{Results}

\subsubsection{Manipulation Checks}

The manipulation of review valence (i.e., two-sided review vs. one-sided review) was successful. There was no significant difference in the question of positivity for these two groups $(M$ two-sided $=4.74, M$ one-sided $=$ 4.69, $F(1,113)=.29, p=.865)$. However, for the question of negativity, the two-sided review 
was evaluated higher than the one-sided review ( $M$ two-sided $=4.68, M$ one-sided $=2.06$, $F(1,113)=145.91, p=.000)$. This indicates that the two-sided review was recognized as both positive and negative compared to the one-sided review, and that the one-sided review was perceived more biased toward positive than the two-sided review.

\subsubsection{Attitude toward Review}

Results of one-way ANOVA showed that participants reported higher positive attitude toward the review when the review was twosided (vs. one-sided) $(F(1,113)=22.90, p<$ $.05)$, supporting H1. Specifically, participants showed more positive attitude toward the review when two-sided reviews were presented ( $M$ two-sided $=4.57)$ than when one-sided reviews were presented $(M$ one-sided $=3.67$; see Figure. 3).

\subsection{Discussion}

Study 1 offered preliminary support for hypothesis 1 that attitude toward review will be affected by review valence. Specifically, consumers showed more positive attitude toward the two-sided review (vs. one-sided review). Nevertheless, there was a need to refine experimental stimuli. For example, attitude toward review could be influenced by the length of the message, the quality of photos and words, and so on. To avoid these possible

〈Figure 3〉 The Effect of Review Valence on Attitude Toward Review ( $\mathrm{H} 1$ )

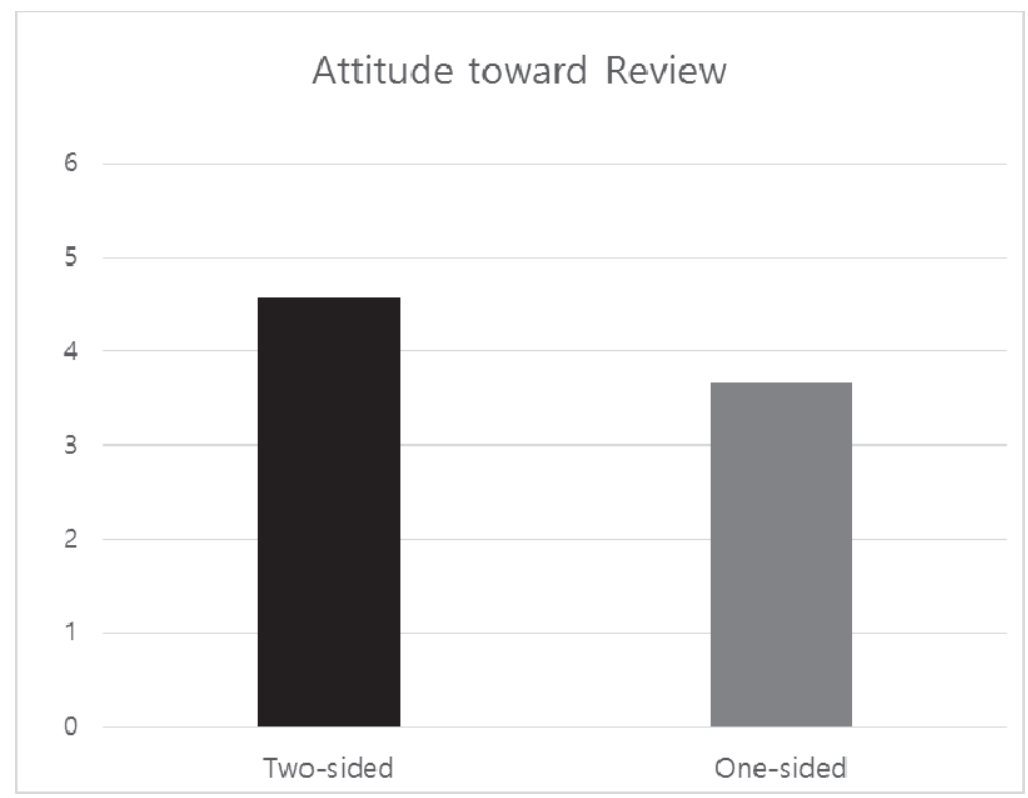

The Effects of One-Sided vs. Two-Sided Review Valence on Electronic Word of Mouth (e-WOM): The Moderating Role of Sponsorship Presence 9 
confounding effects, the next study omitted the middle part of the reviews and eliminated photos to make participants focus on the essential part of review. In addition, study 2 created a fictitious brand to control brand familiarity. Further, study 2 was designed to verify the underlying mechanism behind the effects. Lastly, sponsorship presence was examined as a moderator of the relationship between review valence and attitude toward review.

\section{Study 2}

\subsection{Method}

\subsubsection{Subjects, Design and Procedure}

A sample of 134 participants were recruited from undergraduate and graduate students in South Korea in exchange for a small amount of incentive. They participated in a scenariobased experiment. They were assigned to conditions in a 2 (review valence: two-sided vs. one-sided) $\times 2$ (sponsorship presence: consumer-initiated vs. firm-sponsored) betweensubjects design. With the exception of some modifications below, the experimental procedure was the same as in study 1 .

For review valence, contents in the review were the same as in study 1 except that photos and intermediate parts of the review were eliminated. Also, a fictitious brand name ("Pills") was used.

When it comes to sponsorship presence, in the consumer-voluntary condition, the following sentence was given at the bottom of the review: "This review is written by a person who purchased the product directly or acquired it from the acquaintance, and there is no commercial transaction with the company." On the other hand, there was the following statement in the firm-sponsored condition: "This review was made by receiving the product and fee from the company." The phrase which displays the sponsorship presence was presented at the top of the review.

\subsubsection{Scales}

Attitude toward review was measured using an average of four 7-point items (Park \& Lee, 2008). The items were "When I make a decision about purchasing a body scrub product, the above review will be helpful," "When I make a decision about purchasing a body scrub product, I will read the above review," "When I make a decision about purchasing a body scrub product, the above review will make me feel confident," and "When I make a decision about purchasing a body scrub product, the above review will make me less troubled." Reliability analysis demonstrated Cronbach's alpha of .81.

Review credibility was measured using three 
7-point items (Appelman \& Sundar, 2015). Respondents were asked to rate the extent to which they considered that the review is authentic, accurate, and reliable.

For manipulation checks, review valence was measured in the same way as in study 1 . As to sponsorship presence, participants rated the degree to which they felt that the review is firm-sponsored or consumer-initiated on a 7-point scale.

\subsection{Results}

\subsubsection{Manipulation Checks}

Across two-sided and one-sided reviews, there was no significant difference in positivity ( $M$ two-sided $=5.01, M$ one-sided $=5.03$, $F(1,132)=.006, p=.936)$. However, for negativity, the two-sided review was evaluated higher than the one-sided one ( $M$ two-sided $=$ 4.59, $M$ one-sided $=2.08, F(1,132)=111.03$, $p=.000)$. Also, as expected, participants who read consumer-voluntary reviews perceived the reviews as more consumer-voluntary than those who read firm-sponsored reviews ( $M$ consumer-voluntary $=4.52, M$ firm-sponsored $=2.85, F(1,132)=31.67, p=.000)$. The participants who read firm-sponsored reviews recognized the reviews as more firm-sponsored than those who read consumer-voluntary ones $(M$ consumer-voluntary $=3.36, M$ firmsponsored $=5.11, F(1,132)=37.58, p=.000)$.

\subsubsection{Main Effect}

A one-way ANOVA on attitude toward review revealed a significant main effect of review valence. In other words, participants had more positive attitudes toward the review when it was two-sided (vs. one-sided) $(F(1,132)$ $=8.18, p<.05)$. This result replicates the findings of study 1 that participants have more positive attitude toward the review that is two-sided ( $M$ two-sided $=5.19)$ rather than one-sided ( $M$ one-sided $=4.59$ ).

\subsubsection{Mediation Effect}

To assess whether review credibility mediates the effect of review valence on attitude toward review, a bootstrapping analysis was conducted using PROCESS model 4 (Hayes, 2013). A result of using 5,000 bootstrapping samples revealed a significant indirect effect of review valence on attitude toward review through review credibility $(b=.51,95 \% C I=[.27$, .83]; See fig. 4).

\subsubsection{Moderation Effect}

The ratings for the four items were averaged to create the perceived attitude toward review. The ANOVA on attitude toward review with the review valence, sponsorship presence, and their interaction revealed a significant interaction effect of review valence $\mathrm{x}$ sponsorship presence 
〈Figure 4〉 Mediation Effect (H2)

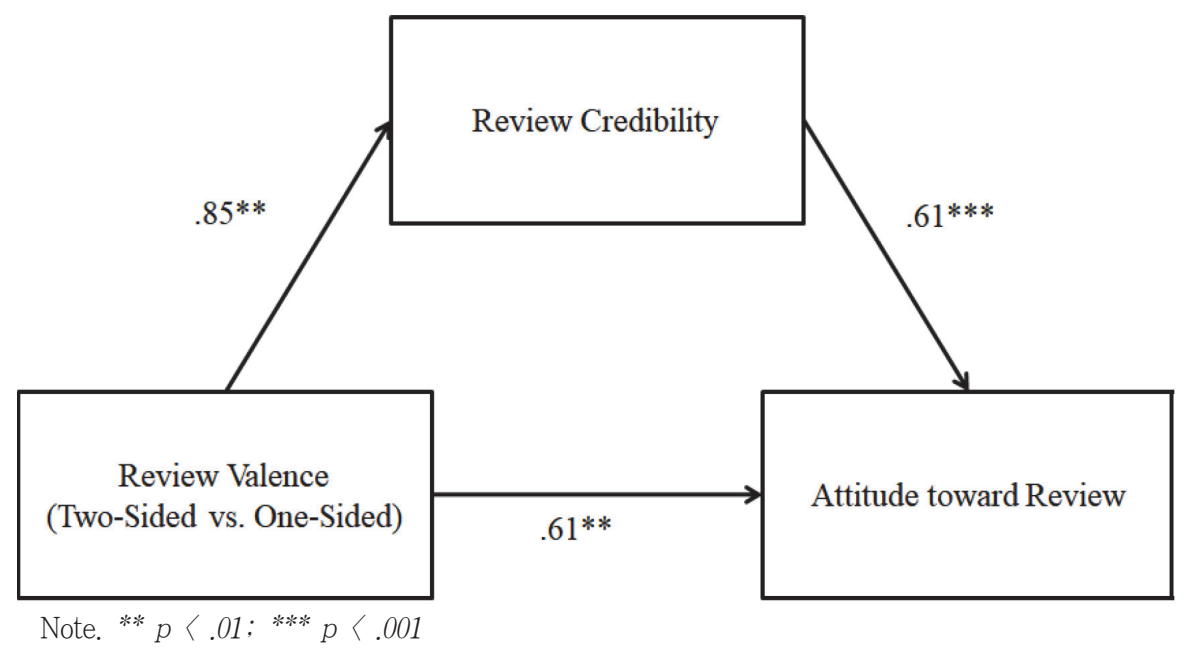

$(F(1,130)=5.32, p<.05)$. The simple effects test revealed that when the review is firmsponsored, review valence significantly affected attitude toward review $(F(1,130)=14.77$, $p=.000)$. On the contrary, when the review is consumer-voluntary, the effect of review valence on attitude toward review was not significant $(F(1,130)=.42, p=.518)$.

The ANOVA on review credibility with the review valence, sponsorship presence, and their interaction showed a significant interaction effect of review valence $\mathrm{x}$ sponsorship presence $(F(1,130)=6.59, p<.05)$. The simple effects test showed that when the review is firmsponsored, review valence significantly affected review credibility $(F(1,130)=22.62, p=$ $.000)$. On the contrary, when the review is consumer-voluntary, the effect of review valence on review credibility was not significant $(F(1,130)=1.48, p=.226)$.

\subsubsection{Mediated Moderation Effect}

A mediated moderation analysis was performed to test whether review credibility mediates the interaction effect of sponsorship presence and review valence on attitude toward review, using PROCESS model 8. Using 5,000 bootstrap samples, the results affirmed a significant indirect path that was mediated by review credibility $(B=-1.05, S E=.41,95 \% \mathrm{CI}=$ $[-1.86,-.24])$. The direct path turned out to be insignificant $(B=-.34, S E=.33,95 \%$ $\mathrm{CI}=[-.99, .32])$, suggesting that review credibility fully mediated the effect of review valence $\mathrm{x}$ sponsorship presence on attitude toward review. Furthermore, review credibility significantly mediated the relationship between review valence and attitude toward review among participants who read firm-sponsored reviews $(B=.74, S E=.17,95 \% \mathrm{CI}=[.40$, 
1.08]), whereas the mediation effect of review credibility was not significant among those who read consumer-voluntary reviews $(B=$ $.18, \mathrm{SE}=.14,95 \% \mathrm{CI}=[-.09, .46]$; See fig. 5).

\subsection{Discussion}

Study 2 replicated the findings of study 1 . Consistent with $\mathrm{H} 2$, this study validated the mediation effect of review credibility as an underlying mechanism behind the relationship between review valence and attitude toward review. Further, study 2 casts light on the boundary condition of the above effects by affirming the moderating role of sponsorship presence. Review valence had a significant impact on attitude toward review for firmsponsored reviews, but not for consumer-voluntary reviews. In addition, study 2 provided additional evidence regarding the mediating role of review credibility. Review credibility mediated the interaction effect of review valence and sponsorship presence on attitude toward review. These results support $\mathrm{H} 3$.

\section{General Discussion}

\subsection{Theoretical and Practical Implications}

The results of the two experiments suggest that review valence (two-sided vs. one-sided) influences attitude toward review via review credibility. Study 1 and 2 demonstrated that people have more positive attitude toward

〈Figure 5〉 Mediated Moderation Effect (H3)

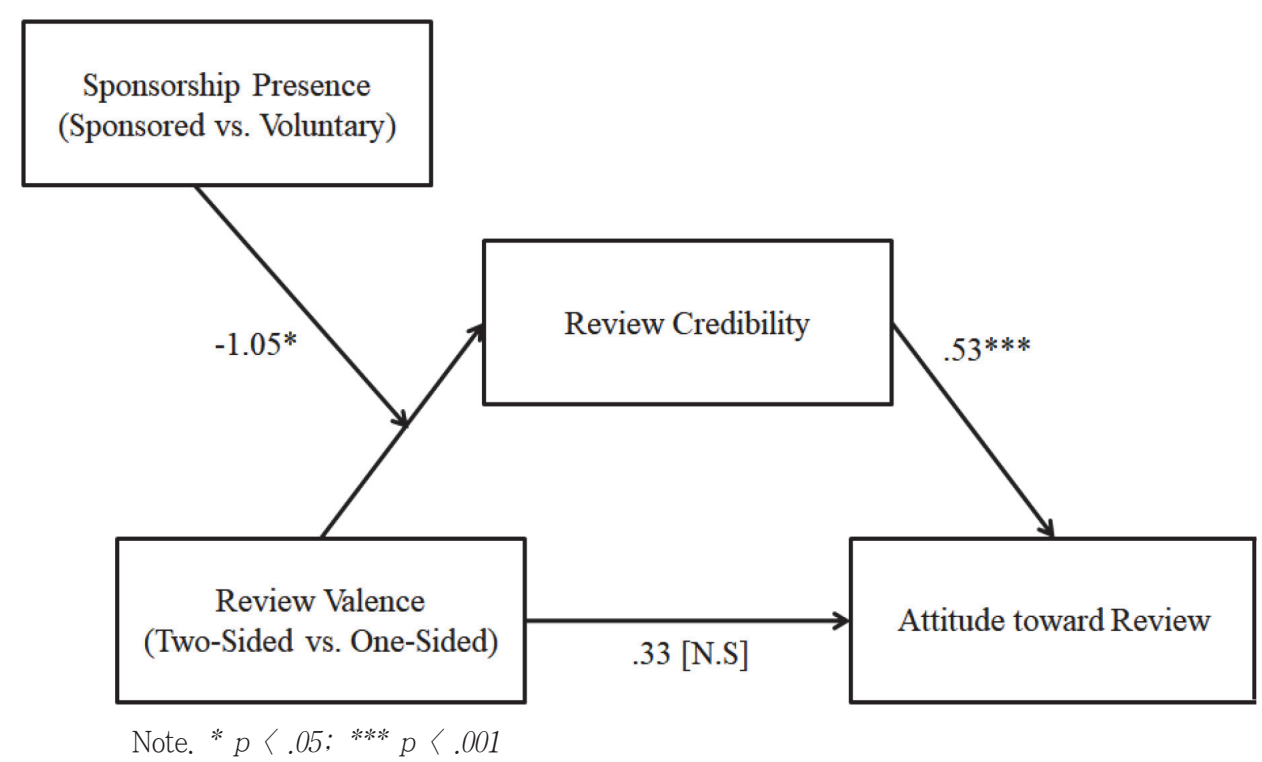


review when the review is two-sided rather than one-sided because they evaluate twosided review as more credible than one-sided review. Also, study 2 validated that the interaction of sponsorship presence and review valence influenced attitude toward review through review credibility. Furthermore, when respondents are exposed to firm-sponsored review, review valence had a significant impact on attitude toward review. However, for those who read consumer-voluntary review, there was no significant difference in attitude toward review between two-sided and one-sided reviews.

The results from the current study provide several theoretical and practical implications on online consumer reviews. First, the present study investigates how consumers respond to online consumer reviews according to review valence. Prior research on review valence has largely focused on one-sidedness: either positive or negative (Clemons, Gao, \& Hitt, 2006; Gershoff, Mukherjee, \& Mukhopadhyay, 2003; Herr et al., 1991; Lee et al., 2009; Skowronski \& Carlston, 1989; Xue \& Zhou, 2010; Yang \& Mai, 2010; ). Even previous studies on twosidedness have failed to produce consistent results. These conflicting findings suggest that further studies are needed. Thus, we investigated the distinct effects produced by review valence (two-sidedness vs. one-sidedness) in order to reduce this gap. Study 1 and 2 confirmed that attitude toward review is affected by review valence. That is, consumers who read two-sided review indicated more positive attitude toward review compared to those who read one-sided review because two-sided review is perceived as more credible than one-sided review.

Second, the current research contributes to the literature on online consumer reviews by identifying the moderating role of sponsorship presence. Prior research on online consumer reviews has mostly paid attention to consumervoluntary review. Little research has examined how consumer-voluntary and firm-sponsored reviews differ in influencing consumers' responses to online reviews. The present study hypothesized and tested the interactive effects produced by review valence and sponsorship presence on attitude toward review via review credibility. The impact of review valence on attitude toward review was stronger for firm-sponsored (vs. consumer-voluntary) review. This is because consumers who read firm-sponsored review perceive lower review credibility and, thus, show more favorable attitude when two-sided (vs. one-sided) review is presented.

Third, the above results present a practical implication for marketers. The current study shows that two-sided review is perceived as more credible than one-sided review and review valence has a significant impact on attitude toward review when firm-sponsored review is given to participants. Thus, managers need to strategically operate online consumer reviews as firm-sponsored reviews have become an essential part of marketing strategy. However, 
there are many issues in the management of online consumer reviews such as distribution of positive online reviews and deletion of negative online reviews. Such unethical behaviors can have the adverse effect of diminishing corporate image and lowering credibility and attitude toward review. Therefore, marketers should manage the online review platforms so not to include only favorable contents. For example, managers can set a limit on one-sided review (only positive messages) and give reviewers a guideline in which it is recommended to contain some negative comments in addition to positive comments.

Lastly, the current research reveals that review credibility fully mediates the interactive effect of review valence and sponsorship presence on attitude toward review. This finding suggests that review credibility is an essential element in forming positive attitude toward review. As described earlier, credibility of messages is perceived while people assess online reviews (Wathen \& Burkell, 2002). Also, it might be easy to encourage consumers to accept the persuasive messages when credibility of the messages is high enough (Lee \& Koo, 2012), and high message credibility may lead to positive evaluation (Cheung et al., 2009; Nabi \& Hendriks, 2003; Zhang \& Watts, 2008). Consistent with prior findings on credibility, the present study suggests that it is strategically critical to boost review credibility on online review platforms.

\subsection{Limitations and Future Research}

Further studies need to be implemented because of several limitations. First, the e-WOM reviews were investigated at a 5:5 ratio of positive and negative comments in the review. However, there might be differences in the magnitude of the effects of review valence according to the ratio of positive and negative messages in the review (e.g., 9:1, 8:2, 7:3). Accordingly, future research should test the magnitude of effects of review valence at more stratified levels.

Second, the present study measured attitude toward review as a dependent variable. Even if the implication of the measured dependent variable is evident, purchase intention and attitude toward brand could be measured. Future studies should take these variables into consideration when measuring dependent variables in the experiment.

Third, the current study considered only the features of online review. However, other factors such as reviewer characteristics and product categories might affect the above relationship. For example, future research can investigate reviewer characteristics such as regulatory focus that might influence the above effects.

〈Received March 6. 2019〉

$\langle$ Accepted July 10. 2019〉 


\section{References}

Appelman, A., \& Sundar, S. S. (2015). Measuring Message Credibility Construction and Validation of an Exclusive Scale. Journalism \& Mass Communication Quarterly, 93(1), 59-79.

Chatterjee, P. (2001). Online Reviews: Do Consumers Use Them? Advances in Consumer Research, 28, 129-133.

Chen, P. Y., Wu, S. Y., \& Yoon, J. (2004). The Impact of Online Recommendations and Consumer Feedback on Sales. Proceedings of International Conference on Information Systems (ICIS), 711-724.

Chen, Y., \& Xie, J. (2008). Online Consumer Review: Word-of-Mouth as a New Element of Marketing Communication Mix. Management Science, 54(3), 477-491.

Cheung, M. Y., Luo, C., Sia, C. L., \& Chen, H. (2009). Credibility of Electronic Wordof-Mouth: Informational and Normative Determinants of On-line Consumer Recommendations. International Journal of Electronic Commerce, 13(4), 9-38.

Clemons, E., Gao, G., \& Hitt, L. (2006). When Online Reviews Meet Hyper-differentiation: A Study of the Craft Beer Industry. Journal of Management Information Systems, 23 (2), 149-171.

Crowley, A. E., \& Hoyer, W. D. (1994). An Integrative Framework for Understanding
Two-sided Persuasion. Journal of Consumer Research, 20(4), 561-574.

Doh, S. J., \& Hwang, J. S. (2009). How Consumers Evaluate eWOM (Electronic Word-of-Mouth) Messages. Cyber Psychology \& Behavior, 12(2), 193-197.

Duan, W., Gu, B., \& Whinston, A. B. (2008). Do Online Reviews Matter? An Empirical Investigation of Panel Data. Decision Support Systems, 45(4), 1007-1016.

Dwyer, P. (2007) Measuring the Value of Electronic Word of Mouth and Its Impact in Consumer Communities. Journal of Interactive Marketing, 21(2), 63-79.

Floyd, K., Freling, R., Alhoqail, S., Cho, H. Y., \& Freling, T. (2014). How Online Product Reviews Affect Retail Sales: A Metaanalysis. Journal of Retailing, 90(2), 217232.

Forrest, E., \& Cao, Y. (2010). Opinions, Recommendations and Endorsements: The New Regulatory Framework for Social Media. Journal of Business and Policy Research, 5(2), 88-99.

Gershoff, A. D. et al. (2003). Consumer Acceptance of Online Agent Advice: Extremity and Positivity Effects. Journal of Consumer Psychology, 13(1-2), 161-170.

Golden, L. L., \& Alpert, M. I. (1987). Comparative Analysis of the Relative Effectiveness of One-and Two-sided Communication for Contrasting Products. Journal of Advertising, 16(1), 18-25+68. 
Granitz, N. A. \& Ward, J. C. (1996). Virtual Community: A Sociocognitive Analysis. Advances in Consumer Research, 23, 163166.

Hayes, A. F. (2013). Introduction to Mediation, Moderation, and Conditional Process Analysis: A Regression-based Approach. New York: Guilford Publications.

Herr, P. M., Kardes, F. R., \& Kim, J. (1991). Article Navigation Effects of Word-ofMouth and Product-Attribute Information on Persuasion: An Accessibility-Diagnosticity Perspective. Journal of Consumer Research, 17(4), 454-462.

Ho-Dac, N. N., Carson, S. J., \& Moore, W. L. (2013). The Effects of Positive and Negative Online Customer Reviews: Do Brand Strength and Category Maturity Matter? Journal of Marketing, 77(6), 37-53.

Hung, K.H. \& Li, S.Y. (2007). The Influence of eWOM on Virtual Consumer Communities: Social Capital, Consumer Learning, and Behavioral Outcomes. Journal of Advertising Research, 47(4), 485-495.

Klein, L. R., \& Ford, G. T. (2003). Consumer Search for Information in the Digital Age: An Empirical Study of Pre-purchase Search for Automobiles. Journal of Interactive Marketing, 17(3), 29-49.

Lee, J., Park, D.-H., \& Han, I. (2008). The Effect of Negative Online Consumer Reviews on Product Attitude: an Information Processing View. Electronic Commerce Research and
Applications, 7(3), 341-352.

Lee, K. T., \& Koo, D. M. (2012). Effects of Attribute and Valence of e-WOM on Message Adoption: Moderating Roles of Subjective Knowledge and Regulatory Focus. Computers in Human Behavior, 28(5), 1974-1984.

Lee, M., Rodgers, S., \& Kim, M. (2009). Effects of Valence and Extremity of eWOM on Attitude toward the Brand and Website. Journal of Current Issues and Research in Advertising, 31(2), 1-11.

Lu, L. C., Chang, W. P., \& Chang, H. H. (2014). Consumer Attitudes toward Blogger's Sponsored Recommendations and Purchase Intention: The Effect of Sponsorship Type, Product Type, and Brand Awareness. Computers in Human Behavior, 34, 258266.

Mutum, D., \& Wang, Q. (2010). Consumer Generated Advertising in Blogs, in Eastin, M., Daugherty, T., \& Burns, N. (Eds.), Handbook of Research on Digital Media and Advertising: User Generated Content Consumption, 248-261.

Nabi, R. L., \& Hendrinks, A. (2003). The Persuasive Effect of Host and Audience Reaction Shots in Television Talk Shows. Journal of Communication, 53(3), 527-543. Park, D. H., \& Lee, J. (2007). Information Direction, Website Reputation and eWOM Effect: A Moderating Role of Product Type. Journal of Business Research, 62(1), 61-67. 
Park, D. H., \& Lee, J. (2008). eWOM Overload and its Effect on Consumer Behavioral Intention Depending on Consumer Involvement. Electronic Commerce Research and Applications, 7(4), 386-398.

Pechmann, C. (1992). Predicting When Twosided Ads Will be More Effective than One-sided Ads: The Role of Correlational and Correspondent Inferences. Journal of Marketing Research, 29(4), 441-453.

Petty, R. D., \& Andrews, J. C. (2008). Covert Marketing Unmasked: A Legal and Regulatory Guide for Practices that Mask Marketing Messages. Journal of Public Policy \& Marketing, 27(1), 7-18.

Phelps, J.E., Lewis, R., Mobilio, L., Perry, D. \& Raman, N. (2004). Viral Marketing or Electronic Word-of-mouth Advertising: Examining Consumer Responses and Motivations to Pass along Email. Journal of Advertising Research, 44(4), 333-348.

Ratchford, B. T., Lee, M. S., \& Talukdar, D. (2003). The Impact of the Internet on the Search for Automobiles. Journal of Marketing Research, 40(2), 193-209.

Rotfeld, H. J. (2008). The Stealth Influence of Covert Marketing and Much Ado about What May be Nothing. Journal of Public Policy \& Marketing, 27(1), 63-68.

Schindler, R. M., \& Bickart. B (2005). Published Word of Mouth: Referable, ConsumerGenerated Information on the Internet, in Haugtvedt, C.P., Machleit, K.A. \& Yalch,
R.F. (Eds), Online Consumer Psychology: Understanding and Influencing Behavior in the Virtual World, 35-61.

Skowronski, J. J., \& Carlston, D. E. (1989). Negativity and Extremity Biases in Impression Formation: A review of explanations. Psychological Bulletin, 105(1), 131-142.

Thorson, K.S. \& Rodgers, S. (2006) Relationships between Blogs as eWOM and Interactivity, Perceived Interactivity, and Parasocial Interaction. Journal of Interactive Advertising; 6(2), 5-44.

Wathen, C. N., \& Burkell, J. (2002). Believe It or Not: Factors Influencing Credibility on the Web. Journal of the American Society for Information Science and Technology, 53(2), 134-144.

Xue, F., \& Zhou, P. (2010). The Effects of Product Involvement and Prior Experience on Chinese Consumers' Responses to Online Word of Mouth. Journal of International Consumer Marketing, 23(1), 45-58.

Yang, J., \& Mai, E. (2010). Experiential Goods with Network Externalities Effects: An Empirical Study of Online Rating System. Journal of Business Research, 63(9/10), 1050-1057.

Yoon, S., \& Kim, J. (2001). Is the Internet More Effective than Traditional Media? Factors Affecting the Choice of Media. Journal of Advertising Research, 41(6), 53-60.

Zhang, W., \& Watts, S. A. (2008). Capitalizing 
on Content: Information Adoption in Two Online communities. Journal of the Association for Information Systems, 9(2), 73-94.

Zhu, J. Y., \& Tan, B. C. (2007). Effectiveness of Blog Advertising: Impact of Communicator Expertise, Advertising Intent, and Product Involvement. Proceedings of International Conference on Information Systems (ICIS), 1-19. 